\title{
Modelling the behaviour of concrete shear walls with BFRP reinforcement
}

\author{
Hamid Rahman ${ }^{1 *}$, Ted Donchev ${ }^{1 *}$, and Diana Petkova ${ }^{1}$ \\ ${ }^{1}$ Faculty of Science, Engineering and Computing, Kingston University London, United Kingdom
}

\begin{abstract}
Corrosion of steel reinforcement in concrete structures is one of the main challenges for the construction industry. FRP reinforcement could be used as alternative to steel reinforcement providing several advantages, such as high resistance to corrosion, high tensile strength and opportunity for developing a more ductile mode of destruction. The last characteristic is extremely beneficial in the aspect of lateral load resisting systems including RC shear walls. The presented modelling results consist of preparing finite element models of reinforced concrete shear walls utilizing Ansys 19.2 - Solid65 element which is capable of both cracking and crushing. The results were verified with experimental medium-scale concrete shear walls reinforced with steel and BFRP bars. The models were loaded under cyclic lateral loading following a modified ATC (Applied Technology Council guidelines for seismic testing) 24 protocol. BFRP reinforced models developed similar ultimate capacity and significantly higher energy dissipation in comparison with steel reinforced models. The promising results could provide a momentum toward construction of shear walls using FRP reinforcement with the aims of improving durability and energy dissipation.
\end{abstract}

\section{Introduction}

The problem of steel corrosion in concrete structures can be overcome by alternative reinforcement of Fibre Reinforced Polymers (FRP) bars. The expectation is that the usage of FRP reinforcement for RC shear walls will result in higher energy dissipation due to their lower Young's Modulus and higher deformability of the FRP. Standards and formal design deficiency is a significant barrier for extensive use of FRP in (Reinforced Concrete) RC [1].

Change in the traditional design philosophy of concrete structures is needed for FRP reinforcement as mechanical behaviour of FRP reinforcement differs from the behaviour of conventional steel reinforcement. FRP materials are anisotropic and are characterized by high tensile strength and only in the direction of the reinforcing fibres, which affects shear behaviour and dowel action of the FRP bars as well as bond performance. Furthermore, FRP materials do not yield and they are elastic until failure and the design procedure must account for a lack of ductility in structural concrete members reinforced with FRP bars [2].

Currently there are areas where there is limited knowledge of the performance of FRP reinforcement including fire-resistance, durability in outdoor or severe exposure conditions, bond fatigue, and bond lengths for lap splices. These are the areas which need further research and additional information according to the ACI 440 committee report on FRP reinforcement (ACI, 2006).

Mohamed et al., [1] evaluated GFRP reinforced shear walls by conducting experiments on concrete shear walls reinforced with GFRP bars. The outcome of those studies shows that GFRP reinforced shear walls are capable of higher energy dissipation in comparison with steel reinforced shear walls [1].

\section{Finite Element Modelling}

\subsection{Model Geometry}

One of the essential components of defining a mathematical model is to define its geometry in a finite element method. The geometry of the model will define how the elements are compiled. The geometry of the shear wall which is the subject of this study was modelled using Ansys 19. Since the shear wall was made of concrete with reinforcement layout in two layers and Ansys "Solid 65" element was used, therefore appropriate modelling is via application of 3D geometry [3].

In modelling the geometry of the shear wall some features that do not contribute significantly in design of the actual model were removed; this is also known as "defeaturing". Therefore the connection details to the strong frame and loading cell were not modelled in Finite Element Analysis (FEA). Connection details are elaborated in Section 3. 


\subsection{Element Selection}

To analyse the crack and crush properties of the shear wall under quasi-static loading, the wall was modelled using solid element and the reinforcement was modelled in link element. Selecting appropriate elements is the most important and fundamental decision that has to be taken before starting the analysis which depends on the geometry of the model and type of loading applied. The geometry of this model was volumetric hence $3 \mathrm{D}$ solid was used for concrete. Solid65 in Ansys is a three dimensional element used to model solids, especially concrete. Using a Link element option allows the analysis of the element in tension, compression and bending of the element. The element will allow definition of the section properties to model the cross sectional shape and accurately predict bending behaviour.

The Solid65 3D option can represent the concrete with and without reinforcement. The solid element is capable of cracking in tension and crushing in compression. The element is defined by eight nodes, each node having three degrees of freedom in the $\mathrm{x}, \mathrm{y}$ and $\mathrm{z}$ directions. The element is capable of analysing the nonlinear properties of the concrete and cracking in three orthogonal directions, crushing, plastic deformation and creep. The geometry, node locations and coordinate system are shown in Figure 1 for Solid65 element. This element is defined by isotropic material properties.

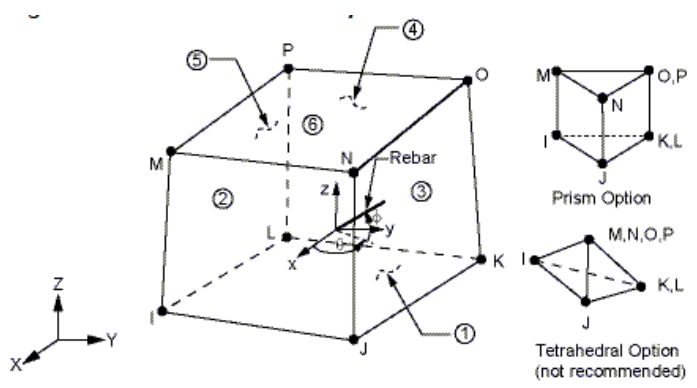

Figure 1: 3D Ansys Solid65 element geometry

Link180 was used to represent the reinforcement in the wall which was an uniaxial tension-compression element with three degree of freedom at each node. The three degrees of free include translation in the nodal $\mathrm{x}, \mathrm{y}$ and $\mathrm{z}$ directions. The element capacities include plasticity, creep, rotation, large deflection, and large strain capabilities. The link element has an option to represent tension-and-compression, tensiononly or compression only states as required. The geometry, node locations and the coordinate system for this element are shown in Figure 2.
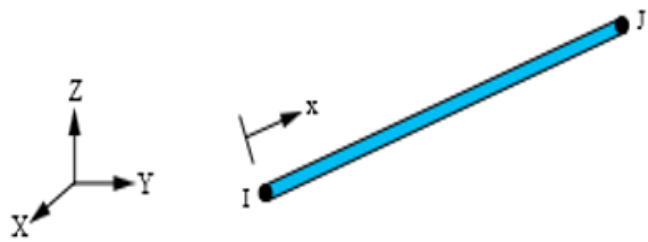

Figure 2: Ansys Link180 element geometry

The element (Link180) is defined by nodes I and $\mathrm{J}$ in (Figure 2), cross sectional area, mass per unit length and material properties. The element supports elasticity, isotropic hardening plasticity, kinematic hardening plasticity, Hill anisotropic plasticity, Chaboche nonlinear hardening plasticity and creep formations. The element can allow change in the cross-sectional area as a function of axial elongation while preserving the volume of the element after deformation which is quite suitable for elastoplastic application. The element also offers the ability to keep the cross-sectional area constant or rigid by facilitating its key options. Other features of the element include support element birth and death, initial state, large deflection, large strain, nonlinear stabilization and stress stiffening.

In summary the elements chosen for analysis of this problem are listed below:

- Solid65 to represent concrete

- Link180 to represent reinforcement.

The basic geometry of the shear wall model is indicated in Figure 3. The concrete volume is modelled using Solid65 element and the reinforcement is modelled using Link180 element by connecting the coincident element nodes. The connection of element nodes by Link180 element generates a perfect bond between the reinforcement and the concrete. The mesh allows for closely spaced nodes in both elements.

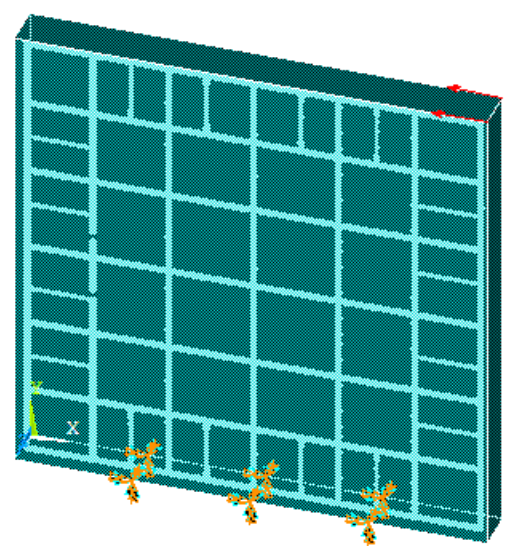

Figure 3: Volume generated by ANSYS for the shear wall model. 
The shear wall model in Figure 3 is a modelling representation of the concrete volume and reinforcement cage as well as the boundary condition and the application force. The cyclic load is applied at the top right corner of the wall representing the cyclic lateral load generated in the case of a heavy earthquake on the building in this case consisting of the modelled reinforced concrete shear wall. The two variation of the shear wall models are listed in Table 1.

For both the concrete and reinforcement elements the real constants and section properties were assigned accordingly. Solid65 was represented by real constant 1 and Link180 was configured with section 1 Rebar, 2 Rebar and 3 Link; user defined. The section 1 represents $10 \mathrm{~mm}$ diameter bars, section 2 represents $6 \mathrm{~mm}$ bars and section 3 represents the link reinforcement. Since the reinforcement is defined as link element (Link180); therefore, the real constants for Solid65 are defined as zero value for models 1, 2, 3 and 4 . The zero value of real constant waives the smeared capacity of the elements in the model.

Table 1: Basic configuration of the RC wall models

\begin{tabular}{|c|c|c|c|c|c|c|}
\hline 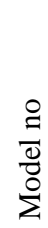 & 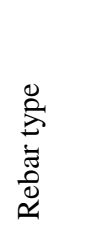 & 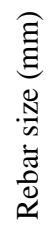 & 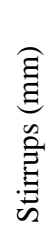 & 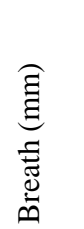 & 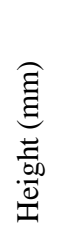 & 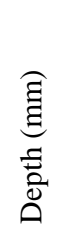 \\
\hline 1 & BFRP & 6 & 6 & 1000 & 1000 & 100 \\
\hline 2 & Steel & 6 & 6 & 1000 & 1000 & 100 \\
\hline
\end{tabular}

\subsection{Material Properties of the Model}

The material properties for each of the three components that are used to make the model in this study were different. The components included the steel, Basalt Fibre Reinforced Polymer (BFRP) and the concrete. The material models for each of the components are described below.

\subsubsection{Steel and BFRP}

The material model for the reinforcements including BFRP bars, steel bars and the stirrups was defined as linear elastic and isotropic material. The following two properties were defined for the steel reinforcement;

- $\quad$ Elastic modulus $\left(E_{s}\right)$

- Poisson's ratio $(v)$

- Yield Stress $\left(f_{y}\right)$

- Tangent modulus $\left(E_{s}{ }^{\prime}\right)$

Poisson' ratio was taken as 0.3 and elastic modulus was taken as $210 \mathrm{GPa}$ for the steel incorporated in the reinforcement of the models [4]. Two wall models were generated using steel rebars. One wall model was reinforced with $6 \mathrm{~mm}$ steel bars and the second model was reinforced with the $6 \mathrm{~mm}$ BFRP bars. All stirrups were $6 \mathrm{~mm}$ steel bars.

The linear and bilinear properties defined for the BFRP reinforcement are outlined below.

- $\quad$ Elastic modulus $\left(E_{s}\right)$

- Poisson's ratio $(v)$

- Yield Stress $\left(f_{y}\right)$

- Tangent modulus $\left(E_{s}{ }^{\prime}\right)$

The above property values were extracted from the manufacturers' brochure for the bars. The information provided by the manufacturer showed that the Poisson's ratio for the BFRP was 0.23 and the elastic modulus was $50 \mathrm{GPa}$ [5]. Two wall models were generated. One wall model was reinforced with $6 \mathrm{~mm}$ BFRP bars and the second model was reinforced with $10 \mathrm{~mm}$ BFRP bars. The bar properties are summarized in Table 2 below. All stirrups incorporated were $6 \mathrm{~mm}$ steel bars.

Table 2: Material Properties of Steel and BFRP

\begin{tabular}{|c|c|c|c|c|c|}
\hline \multirow[b]{2}{*}{ No } & \multirow[b]{2}{*}{ Name } & \multicolumn{2}{|c|}{ Linear Isotropic } & \multicolumn{2}{|c|}{ Nonlinear Isotropic } \\
\hline & & $\begin{array}{l}E_{s} \\
(\mathrm{MPa})\end{array}$ & $v$ & $f_{y}(\mathrm{MPa})$ & $\begin{array}{l}E_{s}{ }^{\prime} \\
(\mathrm{MPa})\end{array}$ \\
\hline 1 & Steel & $210 \times 10^{3}$ & 0.3 & 500 & 2100 \\
\hline 2 & BRFP & $50 \times 10^{3}$ & 0.23 & 1000 & 500 \\
\hline
\end{tabular}

\subsubsection{Concrete}

The material properties for the concrete were defined as nonlinear to reflect the actual inelastic nature of the concrete. So in addition to the elastic properties as defined for the reinforcement, nonlinear properties are also defined. The following linear properties were defined for the concrete:

- Poison's ratio $(v)$

- Elastic modulus $\left(E_{c}\right)$

The Poisson's ratio for the concrete material was assumed to 0.2 for all four models [6]. In addition to the above, the following properties were defined to demonstrate the crack behaviour when incorporating Solid65 element for the analysis.

- Shear transfer coefficient for an open crack $\left(\beta_{t}\right)$

- Shear transfer coefficient for a closed crack $\left(\beta_{\mathrm{c}}\right)$

- Ultimate uniaxial tensile stress $\left(f_{t}\right)$

- Ultimate uniaxial compressive stress $\left(f_{c}\right)$ 
The mean compressive cylinder strength and modulus of elasticity were calculated according to EN 1992-11:2004 [8]. The compressive strength values were obtained from conducting compressive tests. The tension calculation can be calculated as per equations below:

$$
\begin{aligned}
& f_{c m}=f_{c k}+8(\mathrm{MPa}) \\
& f_{c t m}=0.3 \times f_{c k}^{(2 / 3)}<\mathrm{C} 50 / 60
\end{aligned}
$$

Where $f_{c t m}$ is the mean tensile strength and $f_{c m}$ is the mean compressive strength.

The shear transfer coefficient value ranges from 0 to 1 . This coefficient characterizes the crack face conditions. A zero coefficient value generates a smooth crack i.e. full loss of shear transfer. A coefficient value of 1 produces a rough crack i.e. no loss of shear transfer. It is recommended that the shear transfer coefficient for an open crack shall be less than 0.2 to avoid convergence problems [7]. The concrete property values are summarized in Table 3 below. The concrete properties were kept the same for both samples to make sure the types of reinforcement were the only variables under study.

Table 3: Summary of concrete material properties and constants as defined in ANSYS

\begin{tabular}{|l|l|l|l|l|l|l|}
\hline Model & $\begin{array}{l}E_{c} \\
(\mathrm{GPa})\end{array}$ & $\begin{array}{l}f_{c} \\
(\mathrm{MPa})\end{array}$ & $\begin{array}{l}f_{t} \\
(\mathrm{MPa})\end{array}$ & $\beta_{\mathrm{t}}$ & $\beta_{\mathrm{c}}$ & $v$ \\
\hline $1 \& 2$ & 33 & 38 & 2.9 & 0.2 & 1 & 0.2 \\
\hline
\end{tabular}

Default properties of zero were chosen for the following ANSYS configurations which can also be assigned other than the zero values:

- $\quad$ Biaxial crushing stress $\left(f_{c b}\right)$

- Ambient hydrostatic stress, for use with constant $f_{1}$ and $f_{2}\left(\sigma_{h}{ }^{a}\right)$

- Biaxial crushing stress under the ambient hydrostatic stress state $\left(f_{1}\right)$

- Uniaxial crushing stress under the ambient hydrostatic stress state $\left(f_{2}\right)$

- Stiffness multiplier for crack tensile condition $\left(T_{c}\right)$

The ambient hydrostatic stress is required only when $f_{1}$ and $f_{2}$ are not defined as the default value of zero. The above stress state is defined as a function of the principal stress in all three principal directions (Ansys, 2019).

The Solid65 element also requires multilinear isotropic hardening material properties to model the concrete in compression. The multilinear isotropic properties of concrete are calculated utilising following formulae.

- $f=E_{c} \varepsilon / 1+\left(\varepsilon / \varepsilon_{0}\right)$

- $\varepsilon_{0}=2 f_{c} / E_{c}$

- $E_{c}=f / \varepsilon$
Where:

- $f=$ stress at any strain $\varepsilon$

- $\varepsilon=$ strain at stress $f$

- $\varepsilon_{0}=$ strain at the ultimate compressive strength $f_{c}$.

The numerical relationships above including Equations 1, 2 and 3 were used to generate a stressstress curve (Figure 4) for the concrete under compression in this study.

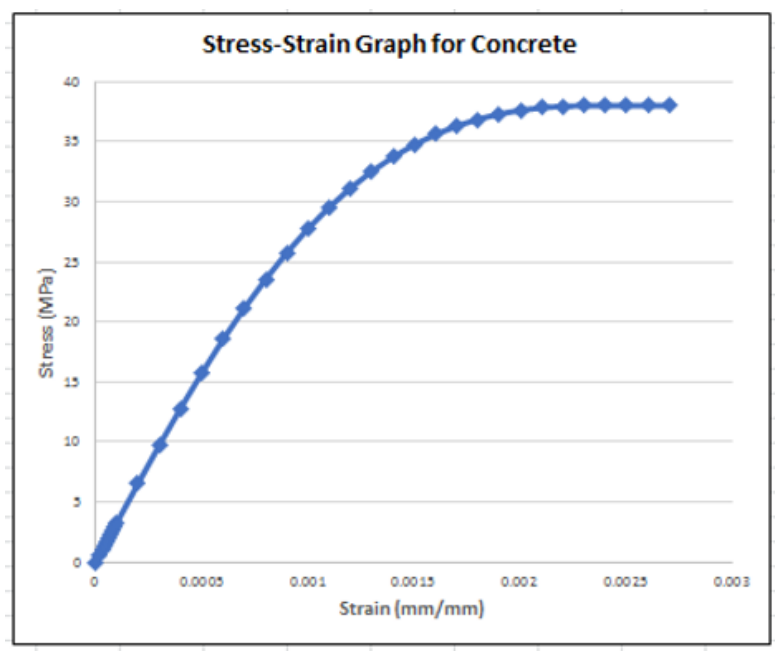

Figure 4: Concrete stress-strain relationship curve for $\mathrm{C} 30 / 37$

The isotropic material properties for the concrete per the above formulae and curve are tabulated below (Table 4);

Table 4: Linear and Multilinear Isotropic properties of concrete and Poisson's Ratio

\begin{tabular}{|l|l|l|}
\hline \multicolumn{3}{|c|}{ Linear Isotropic (C30/37) } \\
\hline \multicolumn{2}{|c|}{$E_{c}(\mathrm{MPa})$} & \multicolumn{2}{c|}{0.2} \\
\hline \multicolumn{2}{|c|}{$v \times 10^{3}$} \\
\hline \multicolumn{3}{|c|}{ Multilinear Isotropic (C30/37) } \\
\hline \multicolumn{4}{|c|}{ Stress $f,[\mathrm{MPa}]$} & Stain $\varepsilon,[\mathrm{m} / \mathrm{m}]$ \\
\hline 0 & 0 & 0 \\
\hline 1 & 3.294 & 0.0001 \\
\hline 2 & 6.551 & 0.0002 \\
\hline 3 & 9.735 & 0.0003 \\
\hline 4 & 12.813 & 0.0004 \\
\hline 5 & 15.757 & 0.0005 \\
\hline 6 & 27.765 & 0.001 \\
\hline 7 & 34.756 & 0.0015 \\
\hline 8 & 37.625 & 0.002 \\
\hline 9 & 37.872 & 0.0025 \\
\hline
\end{tabular}




\subsection{Meshing}

The volumes were meshed using the standard meshing option in the Ansys Workbench platform as shown in Figure 5 below.

There are multiple options for defining the meshing size in the Ansys Workbench platform.

Choosing different sizes of the mesh will provide different results, converging-ability and calculationtime.

The above means that an ideal type of mesh is required to be able to calibrate the model with experimental results and have a converged solution with a reasonable calculation time.

Different meshing strategies were selected to be able to obtain a converged solution in a reasonable time calibrating with the experimental data.

The appropriate size of the mesh that would provide fairly close results to the experimental data is shown in Figure-5 below. This is a "medium" size mesh approximately $3.333 \mathrm{~cm}$. A Medium size mesh is the "coarse and fine" mesh as defined by the Ansys software.

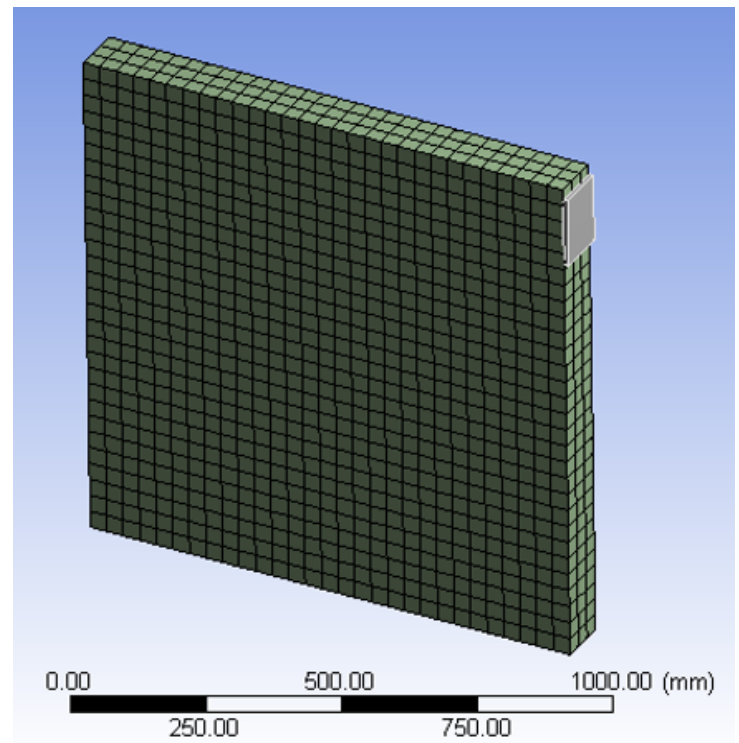

Figure 5: Meshing of the RC shear wall model.

\subsection{Loads and boundary conditions.}

When the basic model was made and the geometry, element, material and meshing were set, then the boundary condition and loads were defined.

Boundary conditions to restrain displacement are required to constrain the model and get a unique solution per condition. It is essential to set the boundary conditions to stop large displacements invalidating the results. The boundary condition was set as per the physical model that was to be developed in the KU civil engineering lab. The boundary conditions were used in all models.
The bottom surface of the model's volume was constrained in all direction to stop rotation and displacement of the bottom plate in all directions. The basic summary of boundary conditions is depicted in the model (Figure 6).

The load was applied to the shear wall as in-plane displacement at top of the wall. The load was applied on the top surface. The load was designed to push and pull the wall in-plane, until an eventual failure.

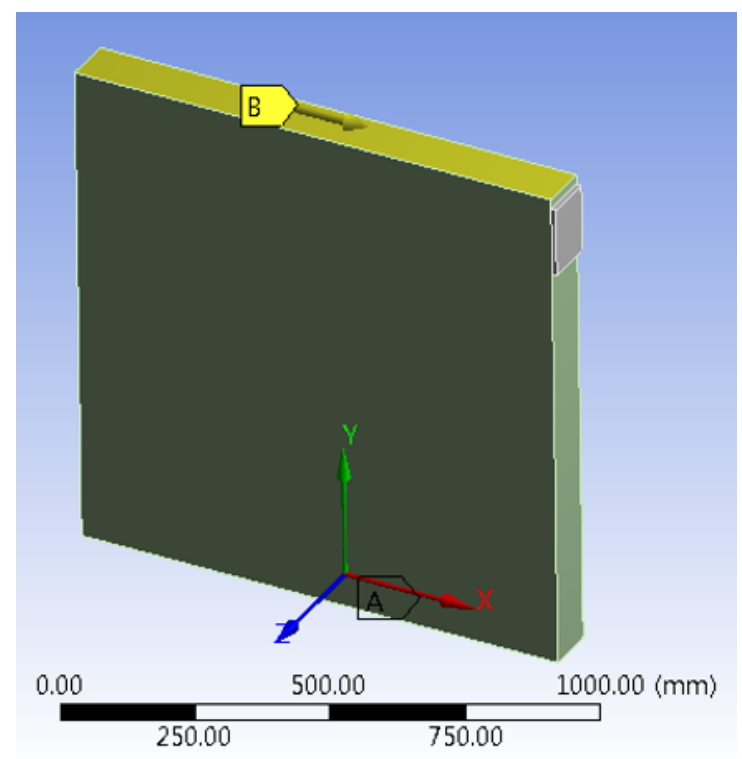

Figure 6: Basic boundary conditions for the wall models fully fixed at bottom and lateral load applied at the top.

The loading cycles applied were the ATC 24 [9] protocol assuming 1 cycle per amplitude and the loading regime used in the modelling session. Fourteen cycles of displacement load amplitudes were sat up to be applied to the test specimen ranging from $0.2 \mathrm{~mm}$ to $40 \mathrm{~mm}$ as indicated in Table- 6 below. No more displacement loads were applied once the specimen failed to sustain more loads.

Table 6 - Load cycle - displacement amplitude table

\begin{tabular}{|c|c|}
\hline Loading Cycles & $\begin{array}{c}\text { Displacement } \\
\text { Amplitude }(\mathrm{mm})\end{array}$ \\
\hline 1 & 0.2 \\
\hline 1 & 0.4 \\
\hline 1 & 0.8 \\
\hline 1 & 1.2 \\
\hline 1 & 2.5 \\
\hline 1 & 3.5 \\
\hline 1 & 5.0 \\
\hline 1 & 10 \\
\hline 1 & 15 \\
\hline 1 & 20 \\
\hline 1 & 25 \\
\hline 1 & 30 \\
\hline 1 & 35 \\
\hline 1 & 40 \\
\hline
\end{tabular}




\section{Experimental tests}

The experimental programme was intended to verify and calibrate the modelling results comprised of testing two 1000x1000x100mm reinforced concrete shear walls under quasi-static loading until failure [10]. One sample was reinforced with steel and the second sample was reinforced with BFRP. The reinforcement details and general dimensions are shown in Figure 7 below.
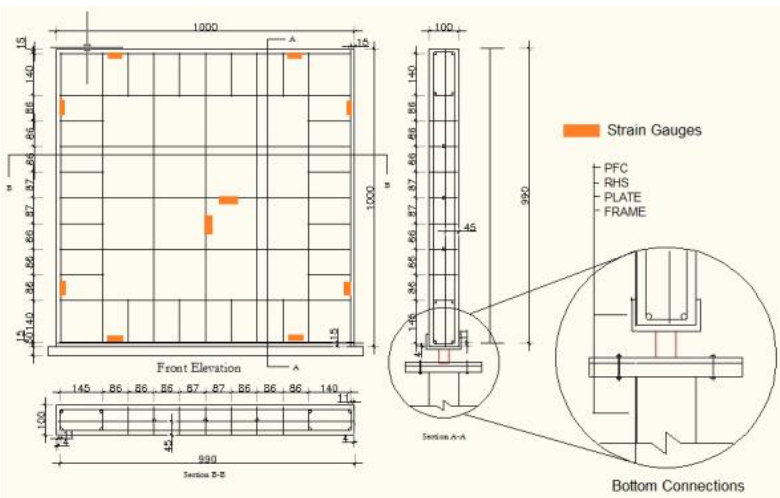

Figure 7: Reinforcement detail and bottom connection and strain gauges.

The strength and properties of the concrete used and the size and properties of the steel and BFRP bars used were the same as the strength, properties and size used to create the FEA model. The loading and boundary condition used were the same as the loading and boundary condition used to create the model.

The samples were cast incorporating PFC (Parallel Flange Channel) steel section at the bottom of the wall with anchoring steel bars. Additional RHS (Rectangular Hollow Sections) was welded to the PFC section on one side and to the perforated steel plate attached to the strong testing frame on the other side (Figure 7).

Each of the shear walls was fixed to the strong frame through the RHS welded to the steel anchor plates at the bottom surface of the wall. This made the base of the wall fixed to the strong frame. The top end of the wall was laterally supported in the out-of-plane direction. Rollers were attached to the strong frame to will allow movement of wall in in-plane direction.

The lateral load was applied through a screw jack model BD Benziler Screw Jack $500 \mathrm{kN}$ to apply the quasi-static loading. The jack was fixed to the reaction frame. The system was installed to insert in-plane horizontal quasi-static load to the loading plate of the specimen. The loading plate was connected to the opposite end of the wall through $10 \mathrm{~mm}$ diameter screw rods bolted to another loading plate installed opposite to the load cell end of the wall to counteract the tensile force applied to the wall by the screw jack when pulling and translate it to compression lateral compression force at the end of the wall opposite to the loading cell. The load was controlled through the data from displacement gauges.
Rosette gauges were added to the concrete surface of the shear wall at the middle of the wall on both sides. The gauges where applied in central surface locations of the wall. The Rosette had a combination of three gauges in two orthogonal directions and one in a diagonal direction to provide the information about the direction and magnitude of the principal strain on the wall surface.

In addition to the above CDS (Cable-extension displacement sensors), LVDT (Linear Variable Displacement Transducers) and dial gauges were also used in many critical positions to capture deformation of the wall due to the cyclic loading and displacement. The CDS' and LVDT's were attached between the strong frame and the specimen. LVDT measured displacements of up to $5 \mathrm{~mm}$ and larger displacements where captured by corresponding CDSs. Dial gauges were used to compare the digitally measured displacements with non-digital readings for double checking.

\section{Results}

The results of the force displacement amplitude are shown in figures $8 \mathrm{a}$ and $8 \mathrm{~b}$ below. The graph is the result of experiments and finite element analysis on the BFRP and Steel reinforced samples.

The comparison of results from the experimental data show that BFRP reinforced model dissipate more energy than the steel reinforced model. The comparison of the FEA results on both types of reinforcement confirms the same. Energy dissipation is the area under the curves in figures $8 \mathrm{a}$ and $8 \mathrm{~b}$.

The results of the experiments show that the BFRP reinforced sample graph continues till $40 \mathrm{~mm}$ displacement amplitude almost constantly after 20 $\mathrm{mm}$ displacement amplitude; however, the steel reinforcement curve shows no result after $15 \mathrm{~mm}$ displacement amplitude because the reinforcement bars broke at this stage.

The result of the FEA shows continuation of the curve after $15 \mathrm{~mm}$ displacement amplitude for the steel reinforced sample. This is because bilinear curve properties were used for the steel reinforcement. The tangent modulus of the bilinear curve will always be more than zero so there will be no breaking of steel bars in a theoretical analysis.

Both BFRP and steel reinforced shear wall FEA models were intensively calibrated to represent the experimental test results obtained. 


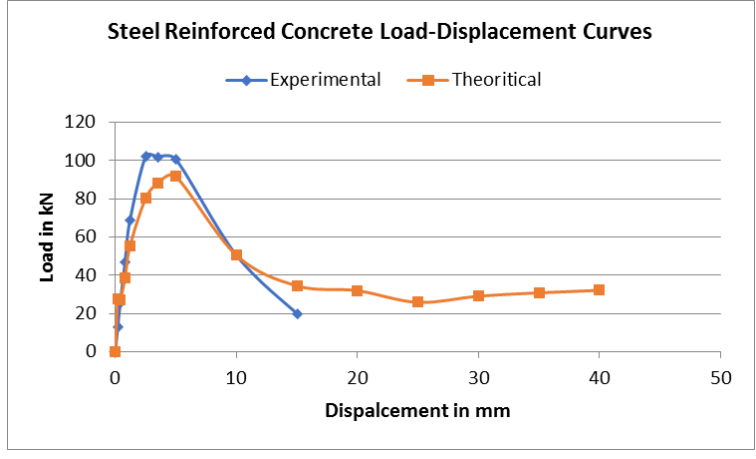

Figure 8a: Experimental and FEA results comparison curves for steel reinforced concrete

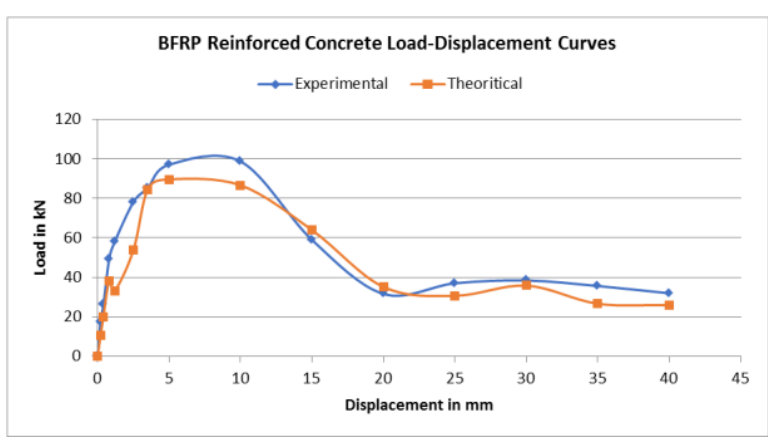

Figure 8b: Experimental and FEA results comparison curves for the BFRP reinforced concrete

\section{Conclusions}

The experiments conducted and the finite element analysis employed confirm the followings:

1. BFRP reinforced shear wall samples develop higher cumulative energy dissipation than the steel reinforced wall samples.

2. The experiment with steel reinforced sample was terminated when reaching the $20 \mathrm{kN}$ residual resistance load at $15 \mathrm{~mm}$ displacement due to developing of a significant crack. The FEA results indicate potential remaining resistance above this level of displacement.

3. Obtained initial similarity between experimental and theoretical results is encouraging. Further refining of the FEA mesh will allow achieving even better correspondence between the obtained results.

\section{References}

1. N. Mohamed, A. Farghaly, B. Benmokrane and K. Neale, Evaluation of GFRP-Reinforced Shear Walls, CSCE General Conference, Quebec Canada, May (2013)

2. ACI-440.1R-06, Guide for the Design and Construction of Structural Concrete Reinforced with FRP Bars, American Concrete Institute (ACI), USA (2006)
3. Ansys help documentations, Ansys help systems, Ansys (2019)

4. J.M. Gere, Mechanics of Material (6th edition), Thomson Engineering, Belmont, CA, USA (2003)

5. MagmaTech, RockBar Brochure, link http://magmatech.co.uk/downloads/RockBar.pd f (2019)

6. FIB-Bulletin No. 43, Structural Connections for Precast Concrete Buildings, Guide to Good Practice, Federation Internationale du Beton (FIB), Lausanne, Switzerland, (2008)

7. D. Kachlakev, T. Miller and S. Yim, Finite element modelling of reinforced concrete structure strengthened with FRP laminates, Final report No. SPR 316, USA, (2001).

8. EN-1992-1-1:2004, Eurocode 2: Design of concrete structures - Part 1-1: General rules and rules for buildings, (2004)

9. Applied Technology Council (ATC) 24: Guidelines for Cyclic Seismic Testing of Components of Steel Structures, Redwood City, CA (1992)

10. H. Rahman, T. Donchev, T. Petkova, D. Jurgelans and G. Hopartean, Behaviour of Concrete Shear Wall with BFRP Reinforcement for Concrete Structures, Proceedings of FRPRCS-14 Conference, Belfast, UK (2019) 